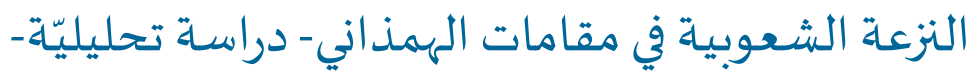

\title{
ربيع محمود ربيع
}

طالب دكتور اه- الجامعة الأردنية- الأردن

rymoon1984@yahoo.com

لقد كان المذهب الديني لبديع الزمان الهمذاني (ت موَهـ) مدارًا للجدل والاختلاف -ولا يزالـ بين النقّاد ومؤرخي الأدب،

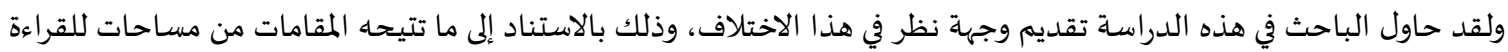

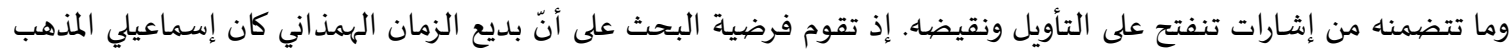

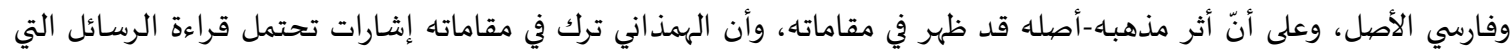
توجهها على ضوء النزعة الشعوبية لصاحب المقامات.

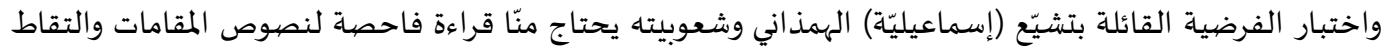

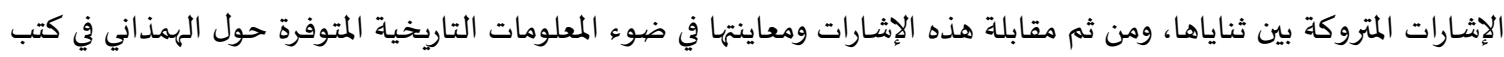
السير والأعلام. وهو ما اتبعاه الباحث

الكلمات المفتاحية: الهمذاني، بديع الزمان، شعوبية، المقامات، إسماعيلية.

\section{(c) (1)}

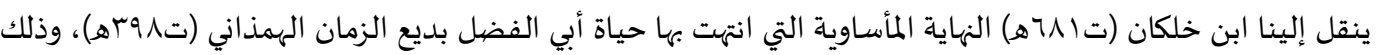

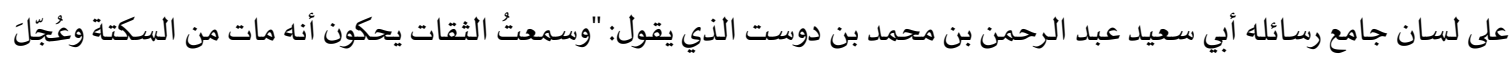

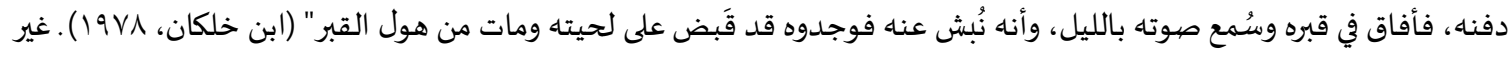

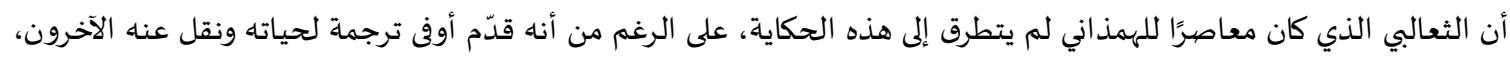

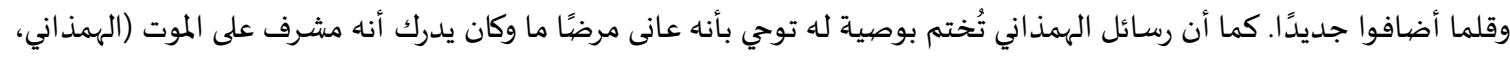

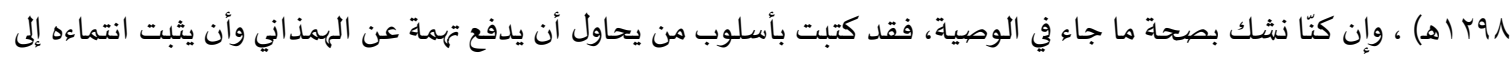
أهل السنة والجماعة، كما سنوضح لاحقا.

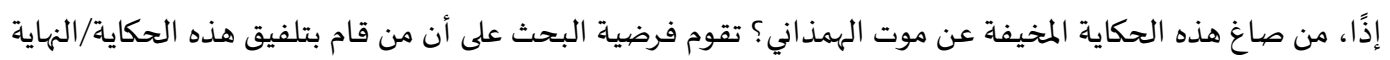

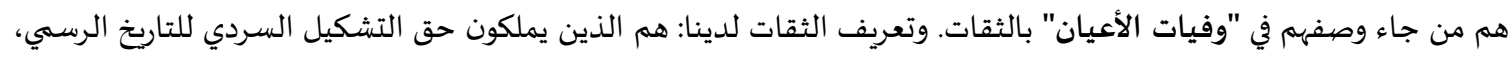

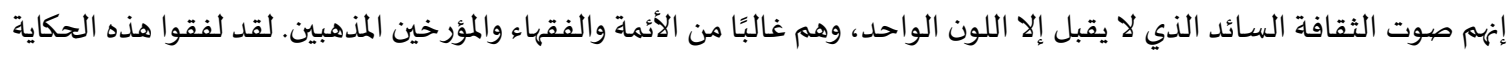

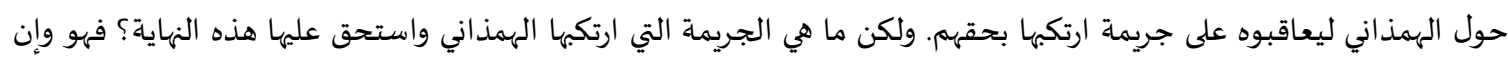

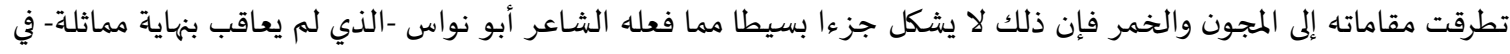

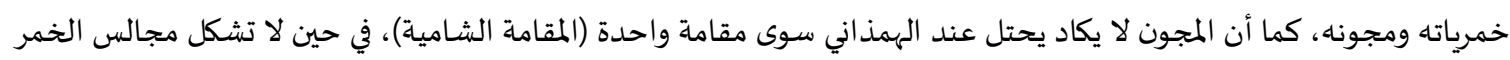

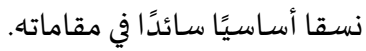

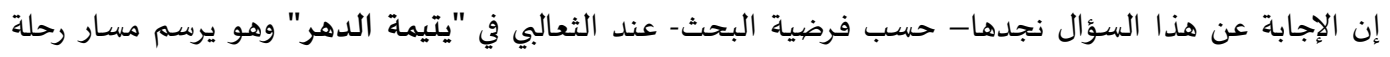

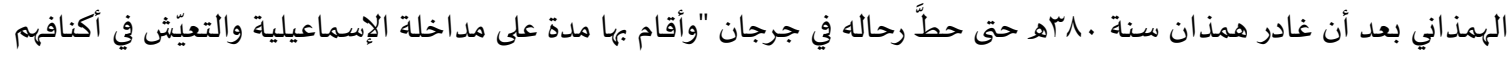

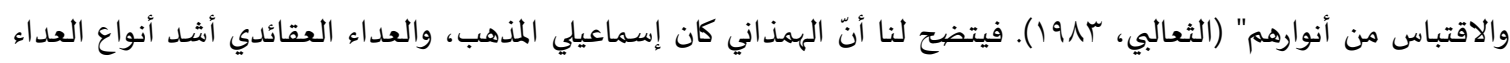

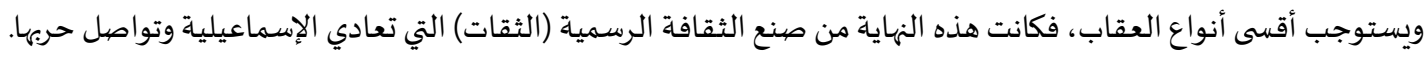

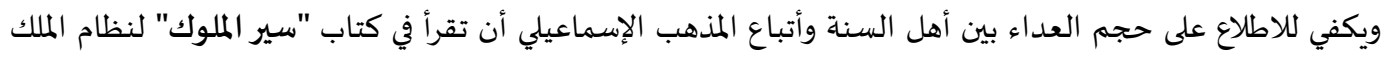

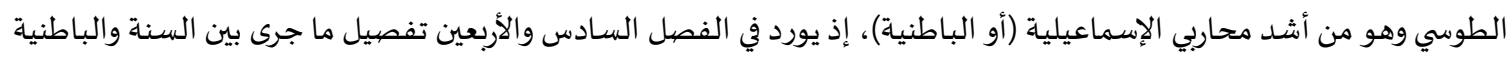


من حروب ومجازر وقعت بينهما، وفي حين لم يتورع أتباع الإسماعيلية عن تنفيذ الاغتيالات بحق قادة أهل السنة، فإن تهمة الباطنية

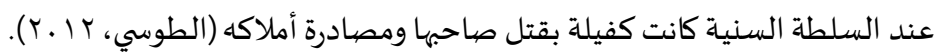

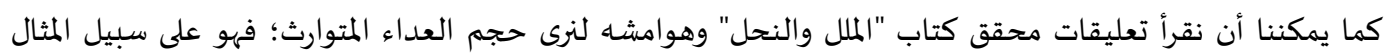
يقتبس فتوى قديمة يضعها في أحد الهوامش تقول: "وحكم الشريعة في طائفة الباطنية، من كان ذا عقيدة إسلامية صحيحة ثم رجع

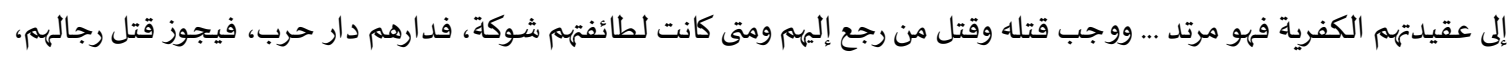

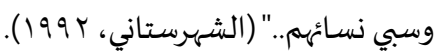
وتأتي حكاية موت الهمذاني في باب تطبيق متأخر لحد الردة عليه، أقامه عليه ثقات الحكائية الحكاية الرسمية. وسيقوم الباحث بقراءة مقامات

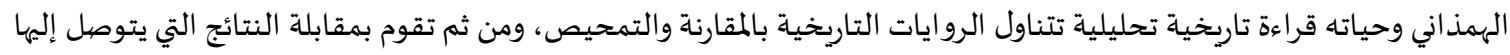

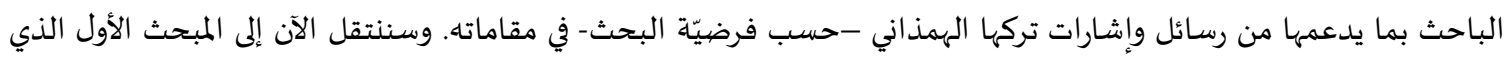
يتناول الإسماعيلية وأبرز سماتها بشكل موجز بما نحتاج إليه ويخدم بحثنا في الجانب التطبيقي على مقامات الهمذاني.

\section{المبحث الأول: الإسماعيلية}

عُرفت الإسماعيلية بأسماء عدة أشهرها: الإسماعيلية والباطنية والفاطمية والقرامطة. ومن الناحية التاريخية برزت

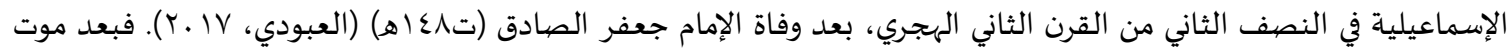

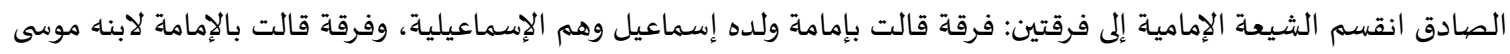

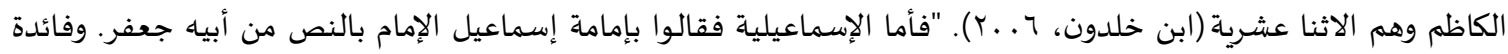

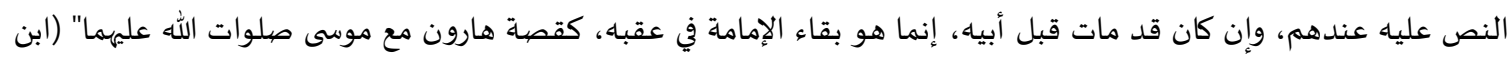

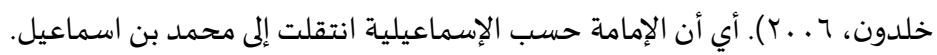
والإسماعيلية من غلاة الشيعة ومتطرفيها، وهم كما يصفهم برنارد لويس "مزيج من نحل صوفية هرطقية الإماعية غالية متطرفة ،

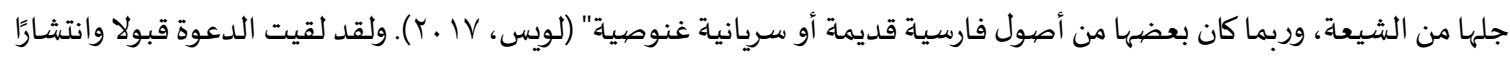

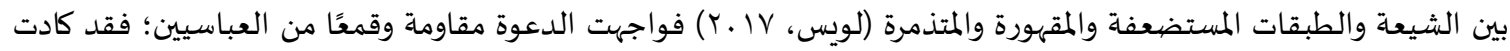
هذه الدعوة أن تطيح بنظام حكمهم، مما "اضطر الإسماعيلية جراء ذلك الهجرةً إلى أماكن متباعدة، فنزلوا في شمال فارس والعراق

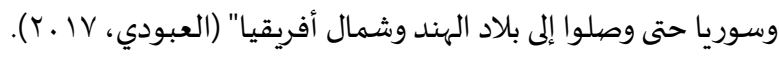

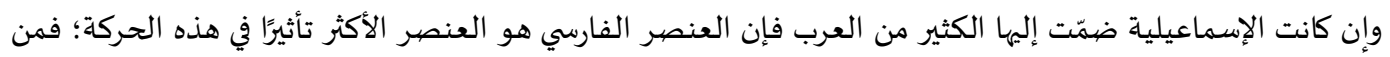

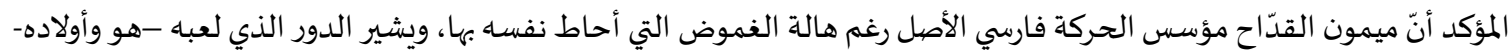

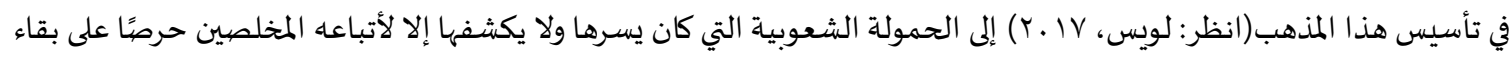

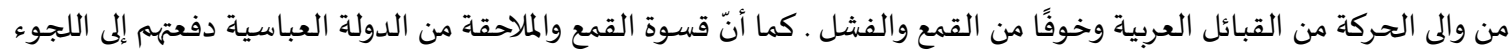

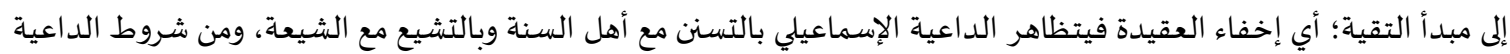

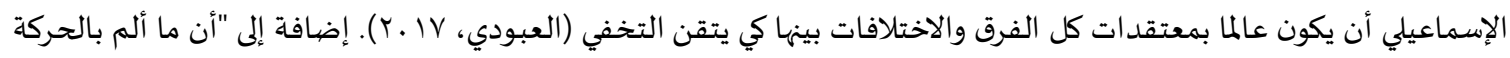

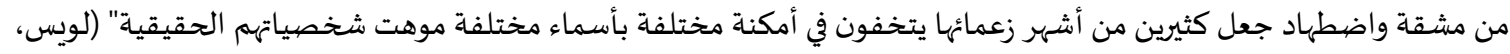

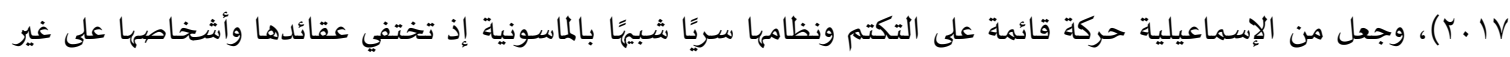

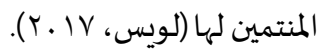

لذلك "نجحت الإسماعيلية في تكوين قوة كبيرة لها جيشها ونظمها وقواعدها" (العبودي، IV . IV)، ويتراتب الإسماعيليون

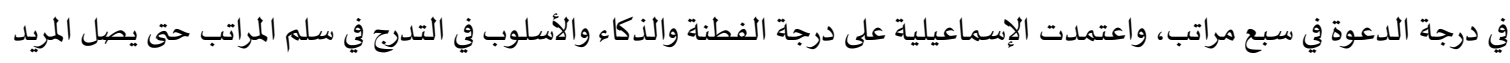

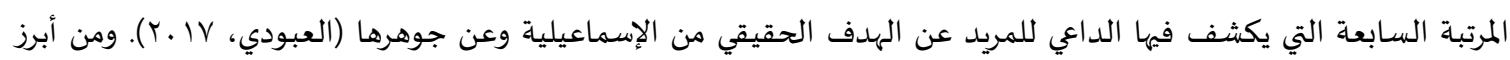

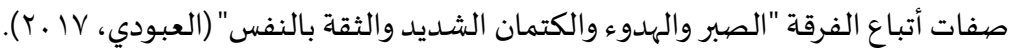

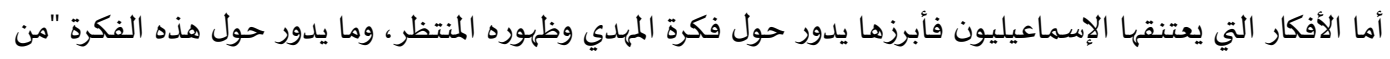

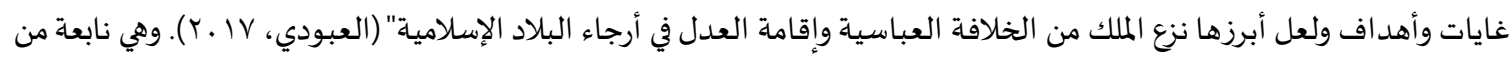

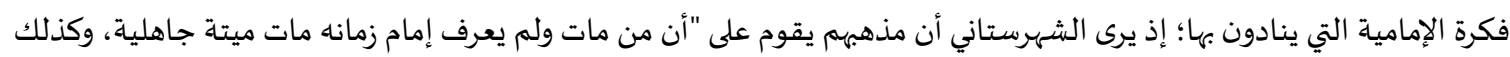

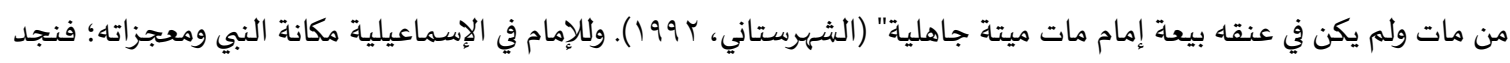
الحسن بن الصباح، على سبيل المثال، يقول: "وأن التوحيد هو التوحيد والنبوة معًا، حتى يكون توحيدا، وأن النبوة هي النبوة والإمامة 
معا، حتى تكون نبوة" (الشهرستاني، rو199). فالإمام له سلطة النبي وله صلاحية إعادة تشكيل العقيدة (التوحيد)، فهم يزعمون أنّ

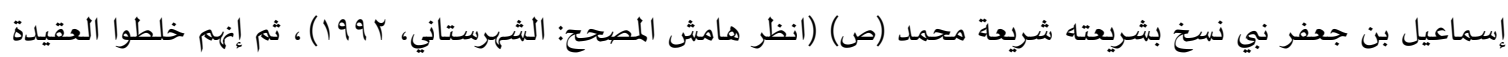
الإسلامية بكلام الفلاسفة (الشهرستاني، بـ 1991).

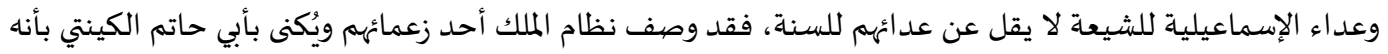

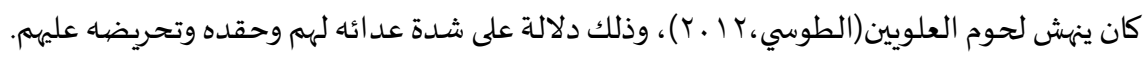

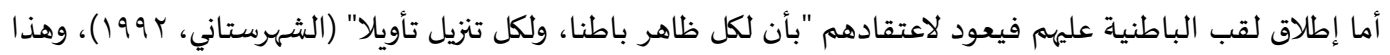

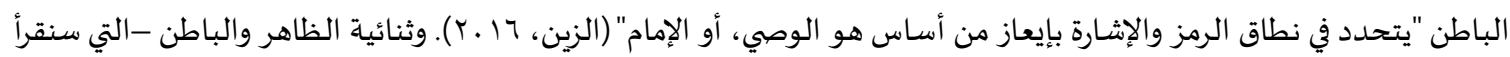

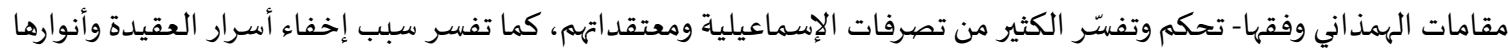

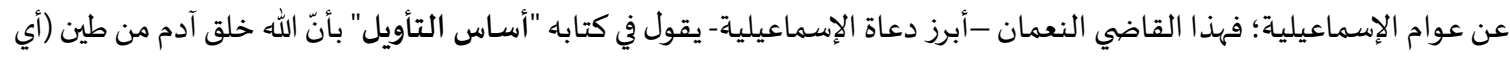

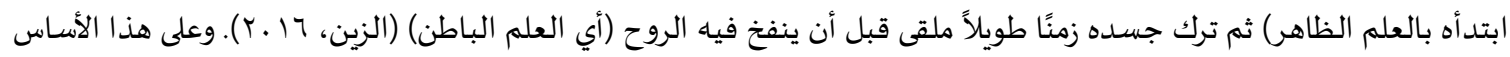

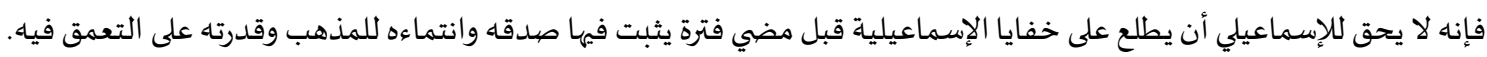

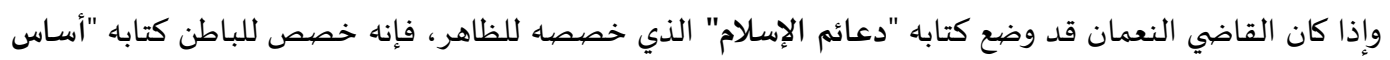

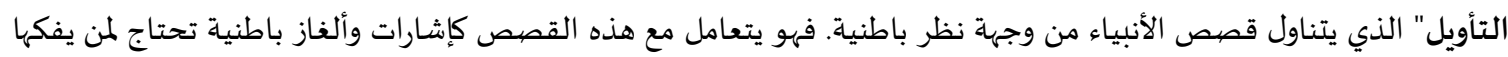

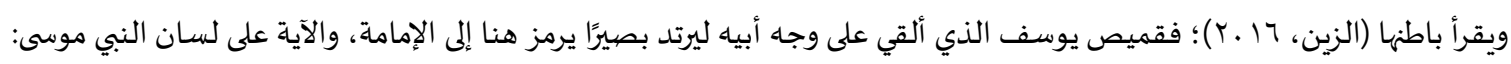

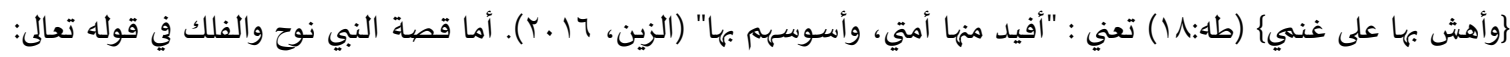

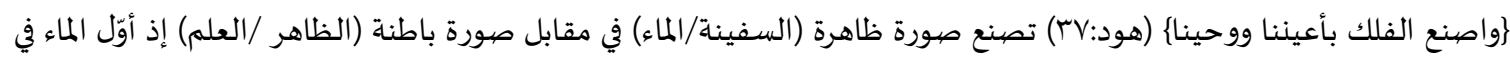

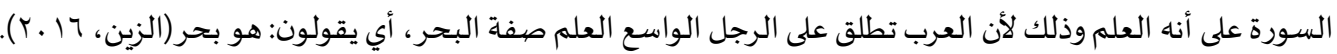

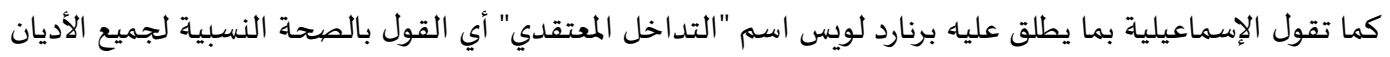

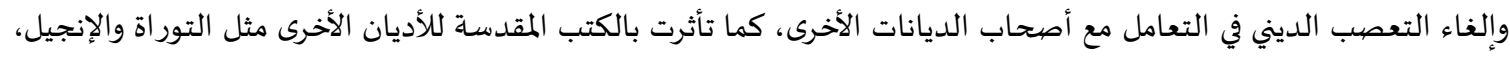

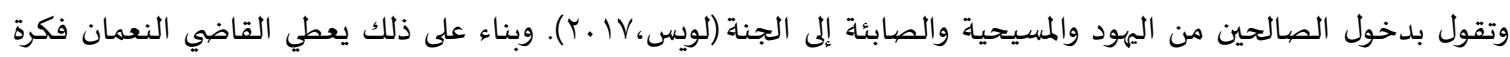

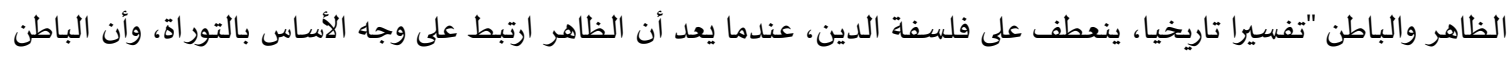

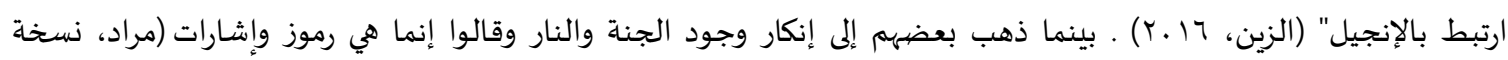

إلكترونية).

ومن أشهر معتقداتهم، التي ستخدمنا أثناء مناقشتنا لشخصية الهمذاني، عقيدة التفويض (التبني الروحي) التي تجعل من أبنا

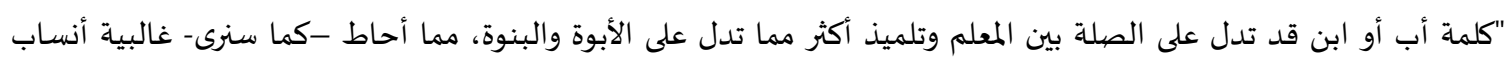

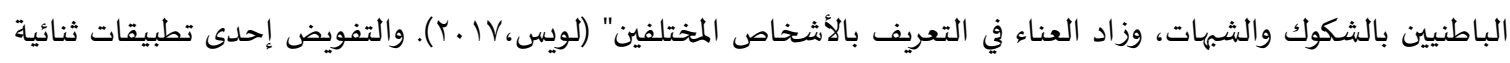

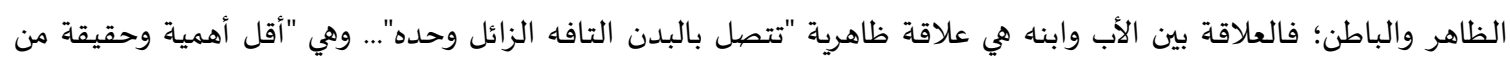

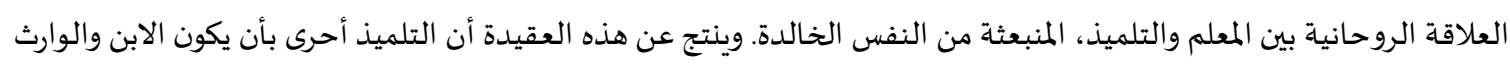

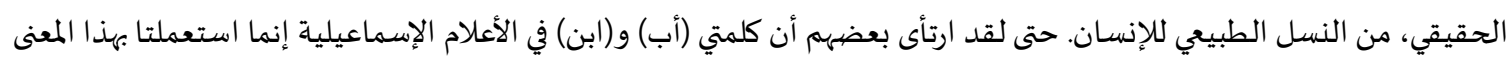

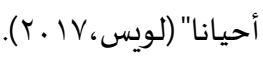

ويرد مثل هذا الكلام صراحة في "رسائل إخوان الصفا" التي تُعد أبرز وثيقة إسماعيلية وصلتنا؛ إذ تقول: "اعلم أن المعلم

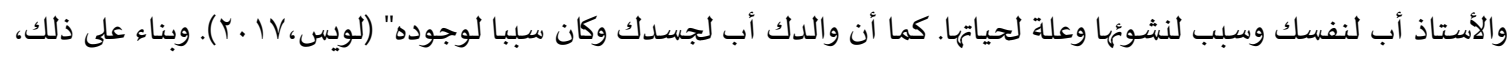

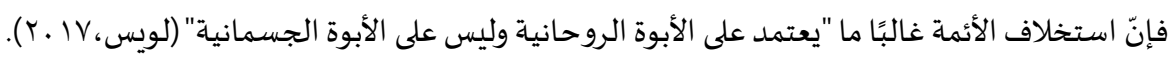

المبحث الثاني: الهمذاني إسماعيليًا

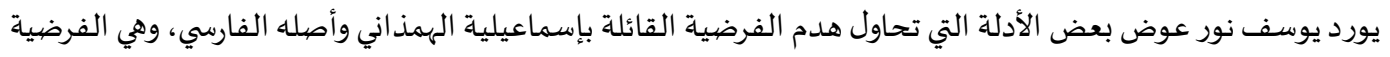

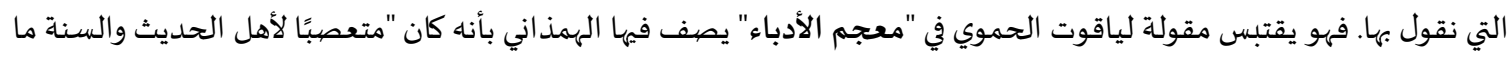

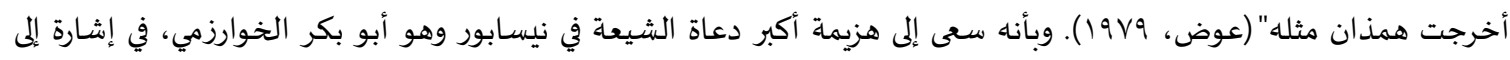

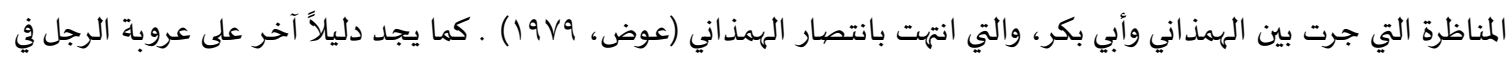

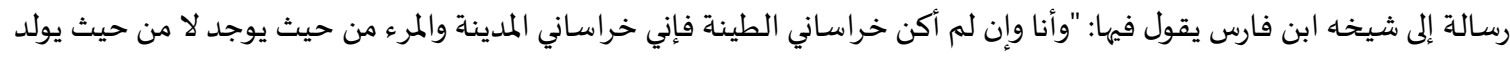


والإنسان من حيث ينبت لا من حيث يثبت" (عوض، 979 (1). ومما يؤكد عروبة الهمذاني عنده أنه وجد أبياتًا شعرية له يهجو فيها

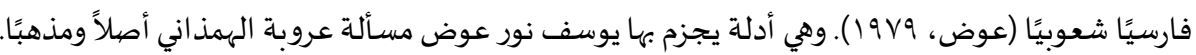

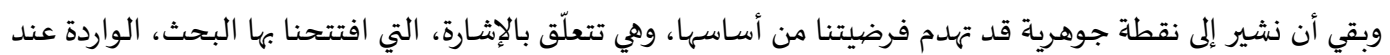

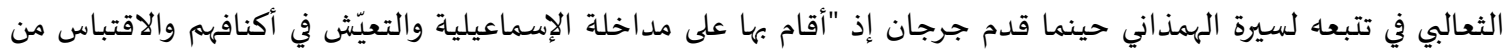

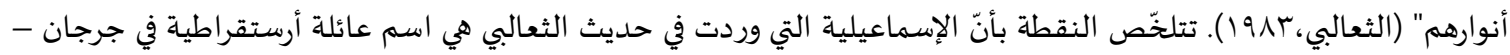
وهذا صحيح- معروفة بالعلم والأدب ومشهورة بالإنفاق على الأدباء والعلماء ولا علاقة لهذه التسمية بالمذهب الإسماعيلي(المبارك،

.$(1971$

ونعترف بأهها أدلة قاطعة للوهلة الأولى، غير أننا بحاجة إلى إعادة ترتيب معلوماتنا استنادًا إلى المعلومات التي قدمناها عن

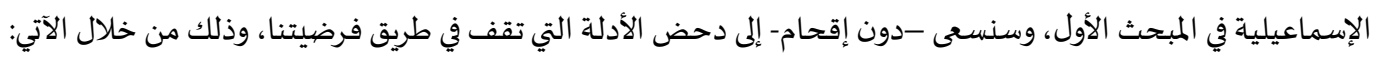
أولاً: إنّ الخصومات الأدبية هي خصومات شخصية الميحية تقوم غالبا على الفردية والتنافس وغير خاضعة لاتساق المذاهب واختلافها؛

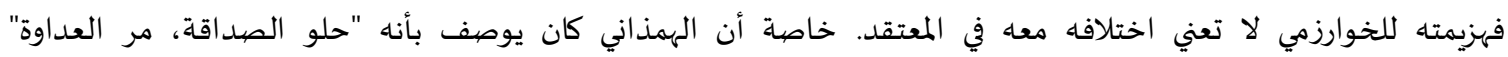

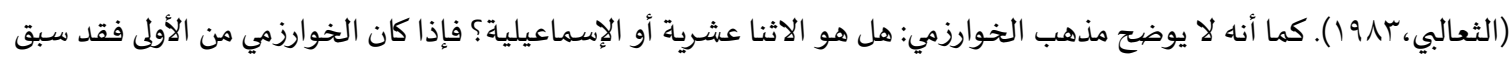

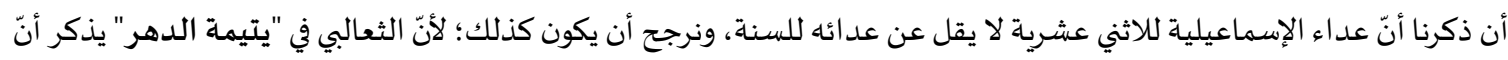

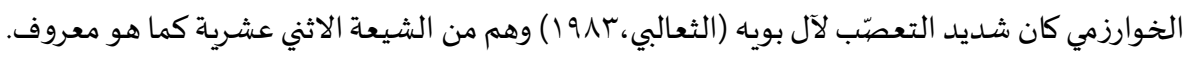

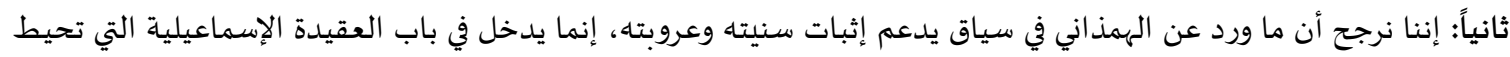

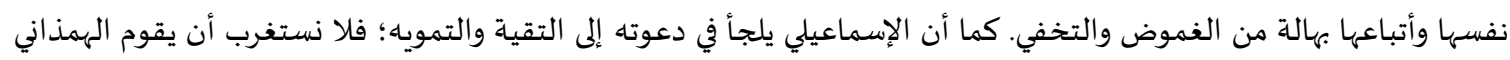

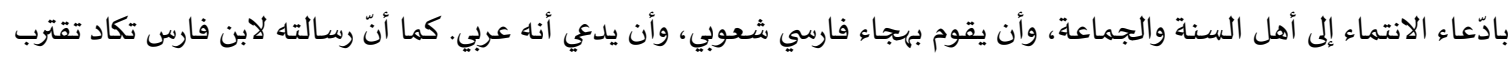

من عقيدة التفويض في مغزاها. ثالثاً: إن عقيدة التفويض التي هي -كما أوضحنا- أساسٌ تقوم عليه الإسماعيلية في انتساب التلميذ إلى أستاذه كما ينتسب الابن

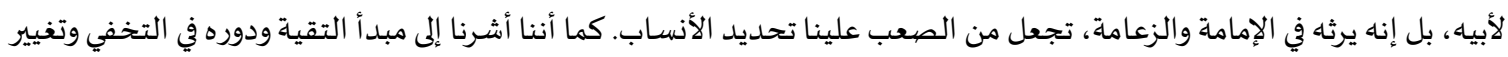

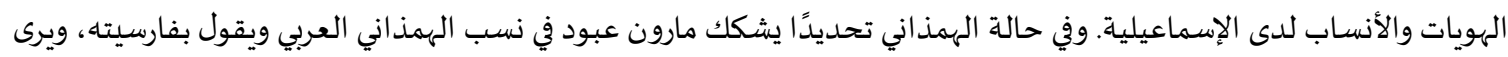

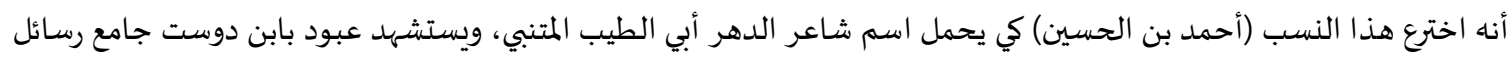

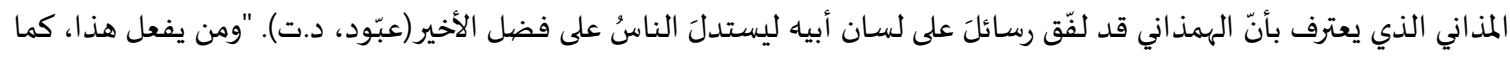

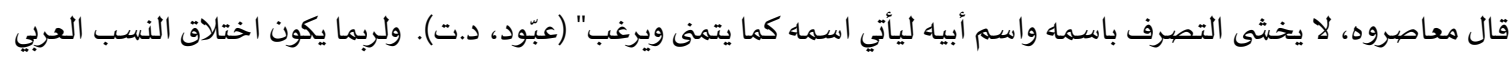

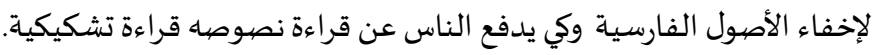

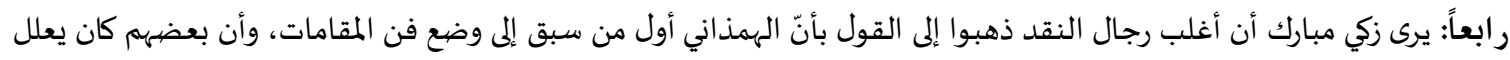

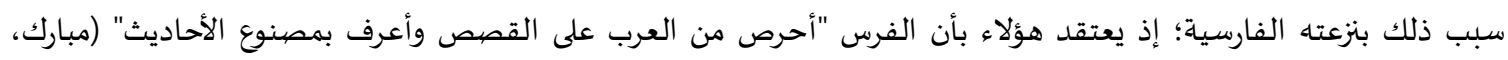

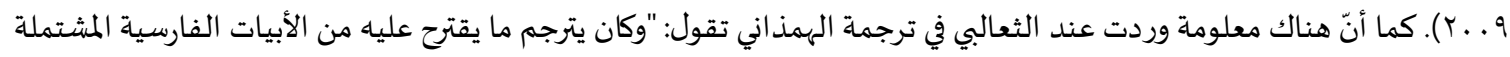

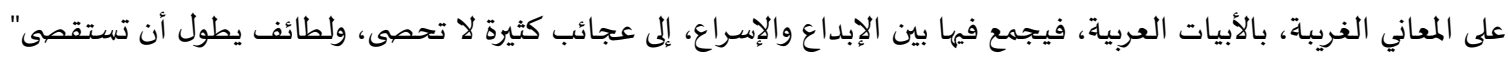

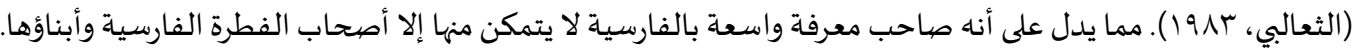

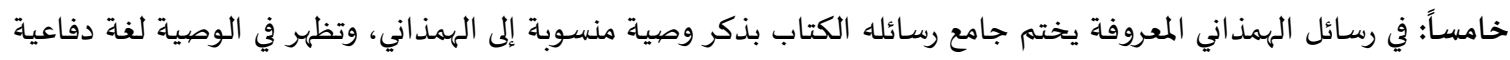

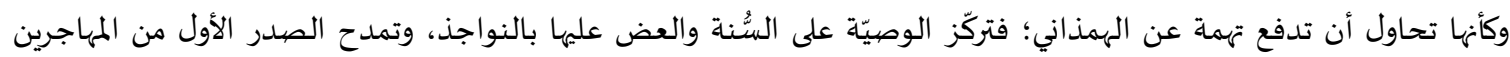

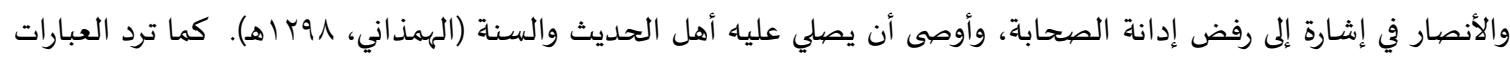

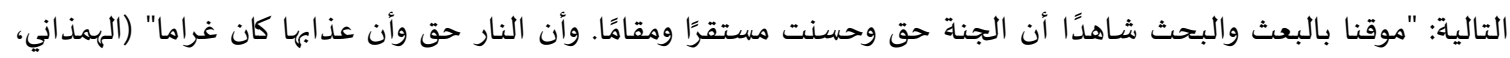

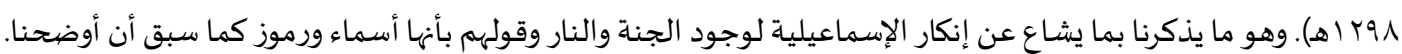

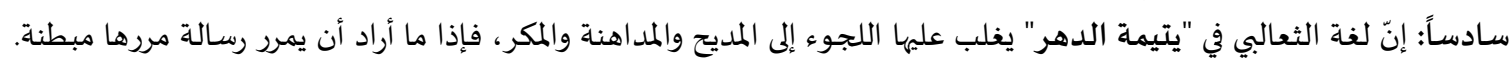
ونجد في كتاب "الوافي بالوفيات" رثاء غريبًا في الثعالبي على لسان ابن دوست (جامع رسائل الهمذاني) لا يخلو من لمز ، إذ يقول:

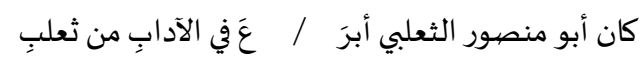

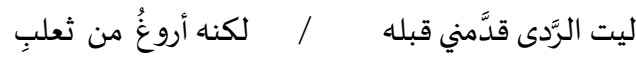

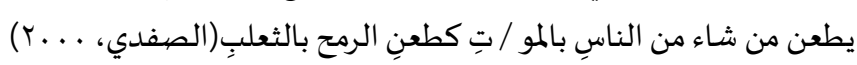




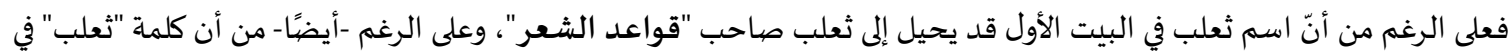

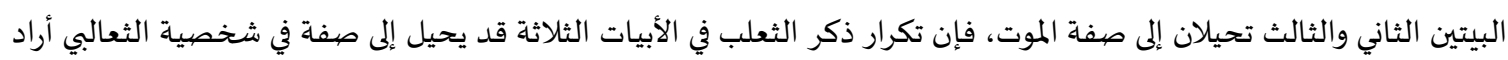
الشاعر أن يذكر الناس بها.

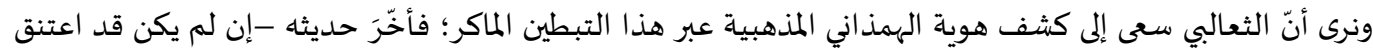

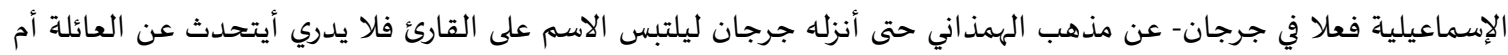

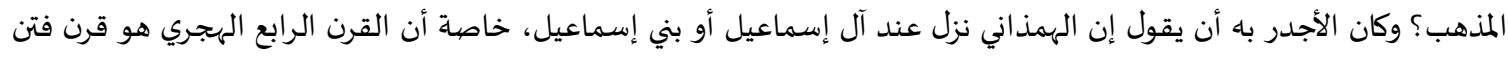

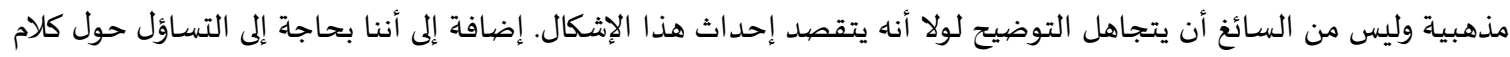

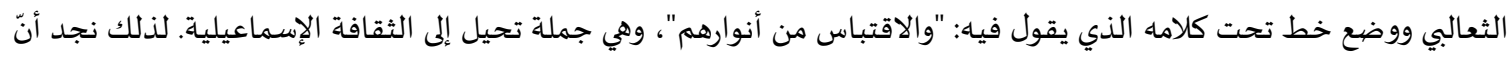

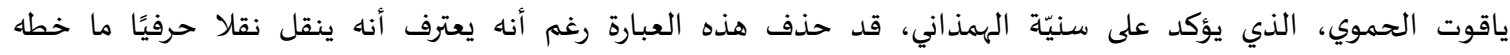

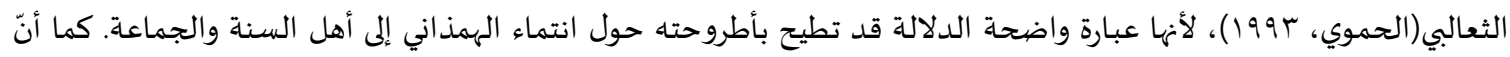

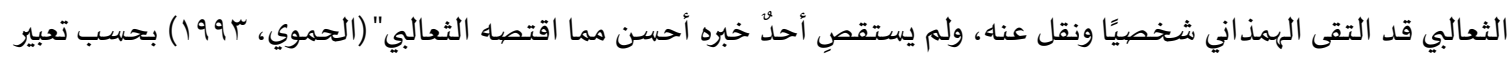
ياقوت الحموي.

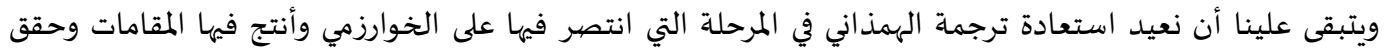

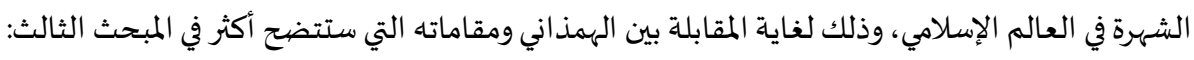

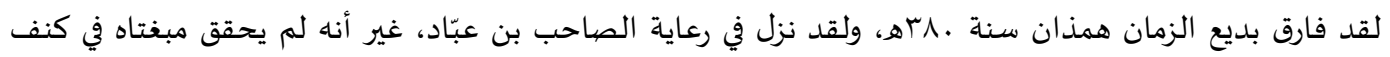

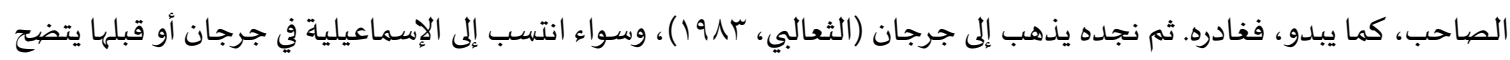

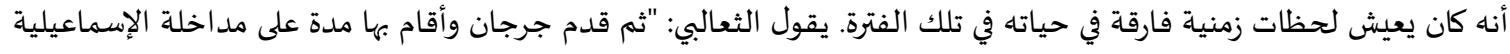

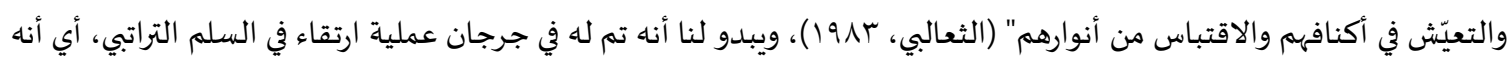

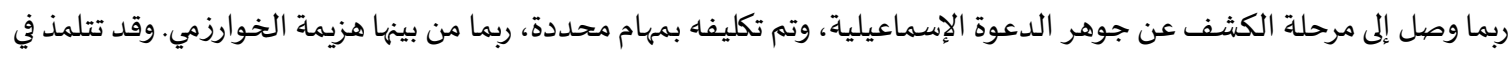

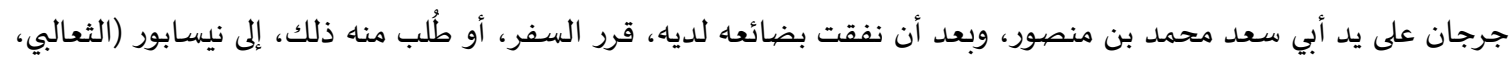

. (1914

غير أن الهمذاني تعرّض في طريقه إلى نيسابور للسطو، إذ خرج عليه بعض اللصوص وسلبوه كل ما يملك، إذ يقول في

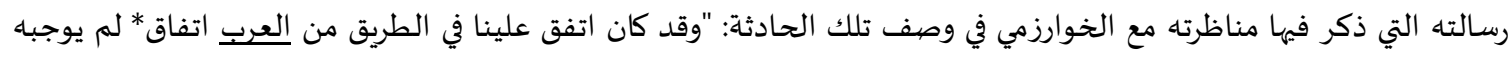

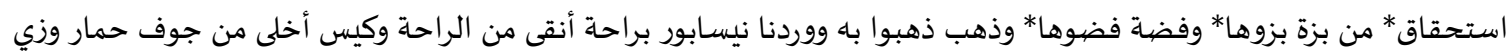

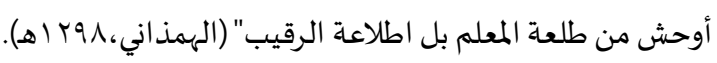

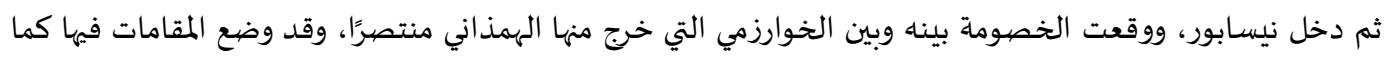

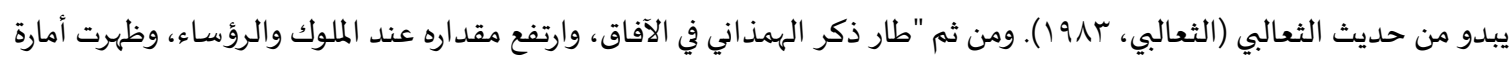

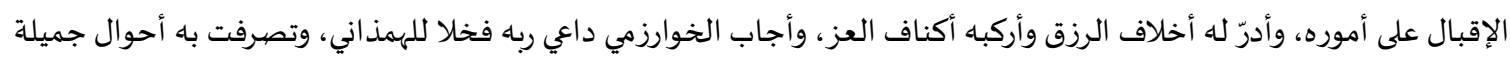

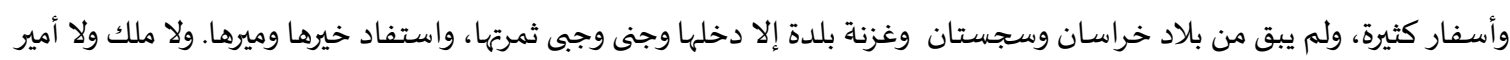

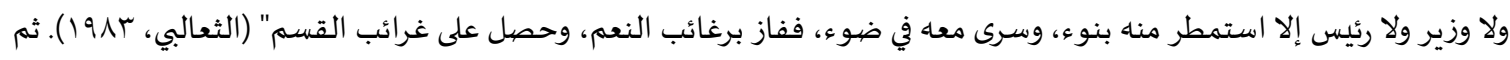

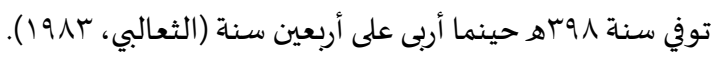

\section{المبحث الثالث: المقامات بين الظاهروالباطن}

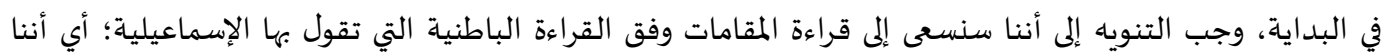

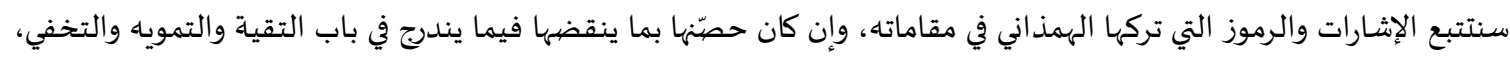

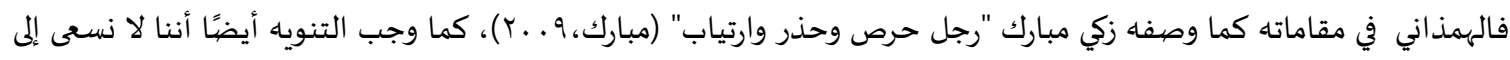

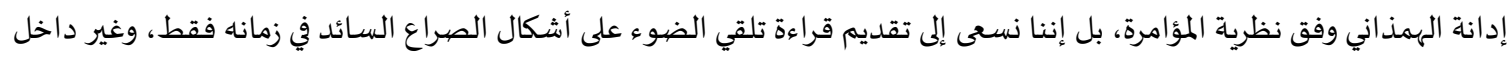
في بحثنا البحث في قضية الحق والباطل.

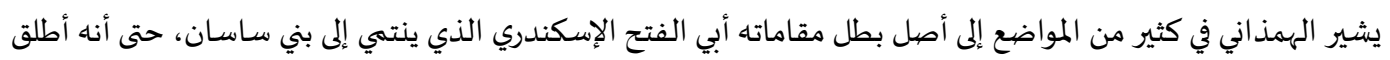

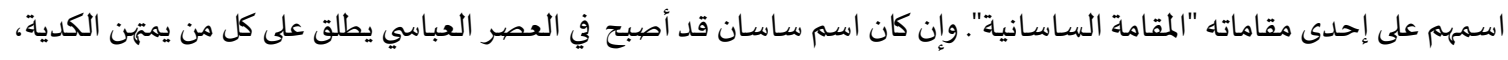

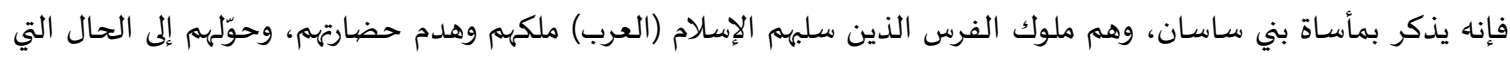


أصبحوا علها؛ إذ أصبحوا مضرب المثل في الكدية والتسوّل. وهذا يحيلنا أيضًا إلى حال الهمذاني حينما قصيد نيسابور؛ إذ خرج عليه

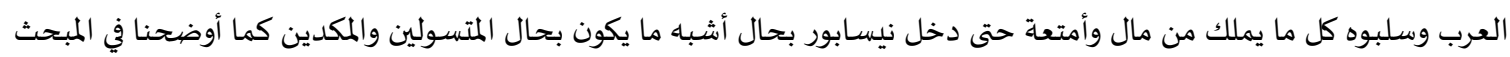

السابق.

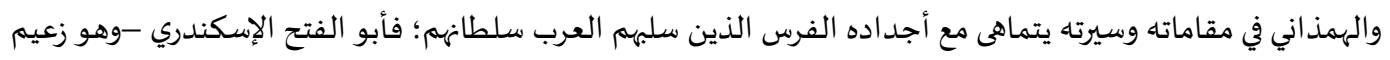

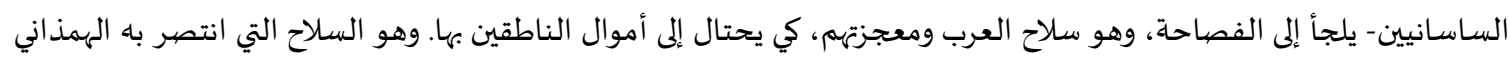

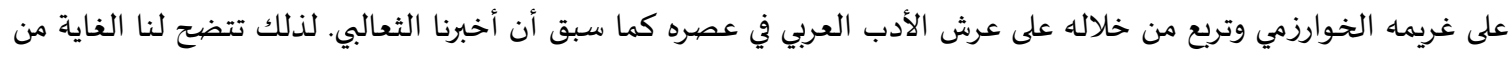

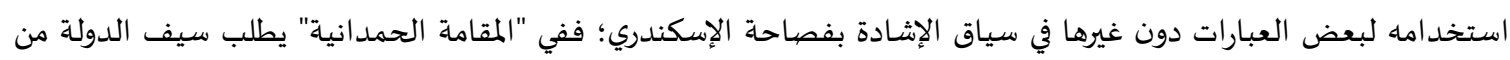

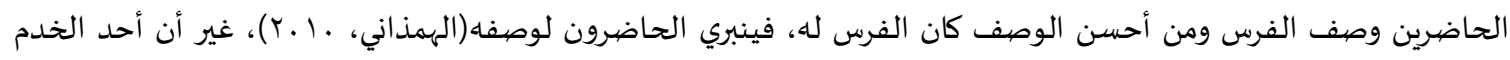

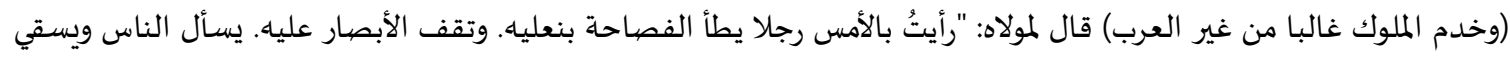

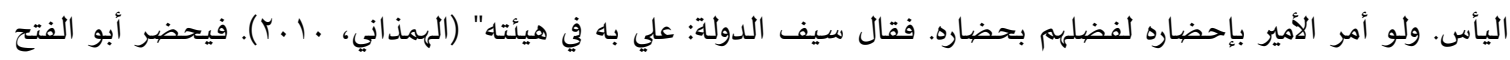

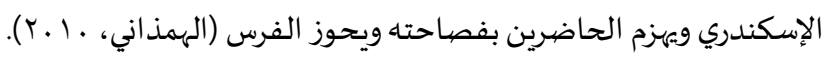

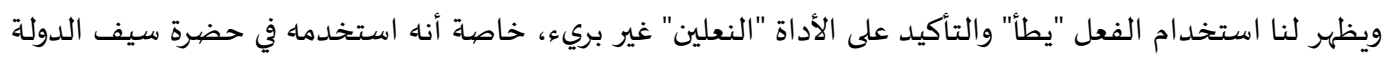

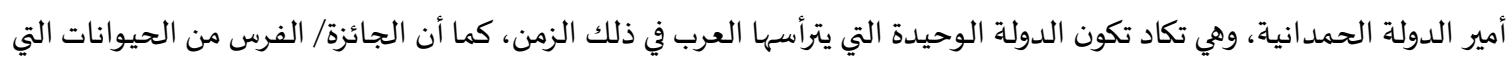

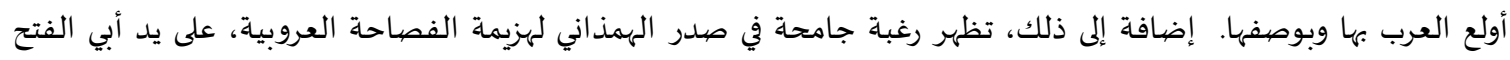

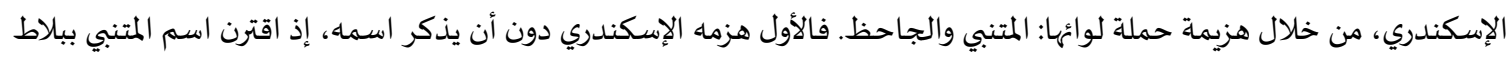

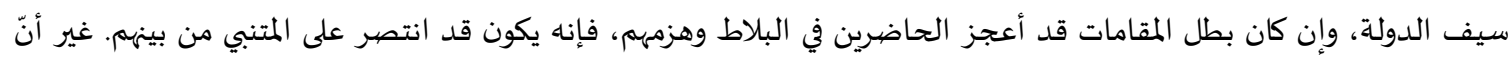

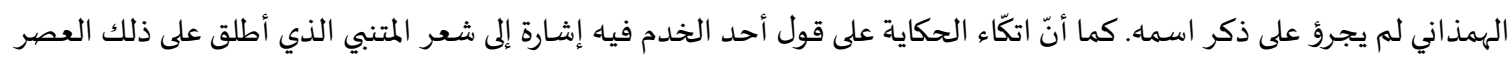

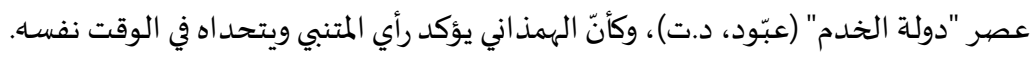

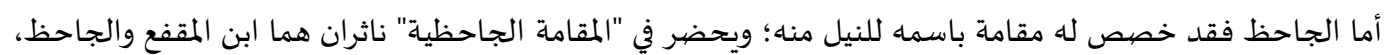

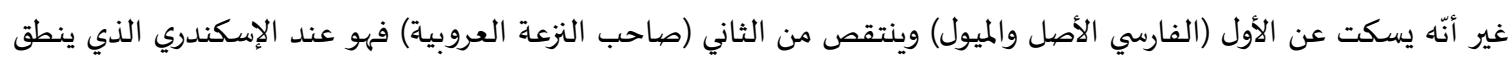

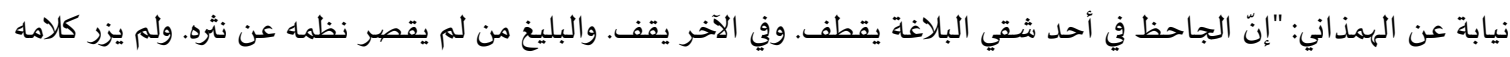

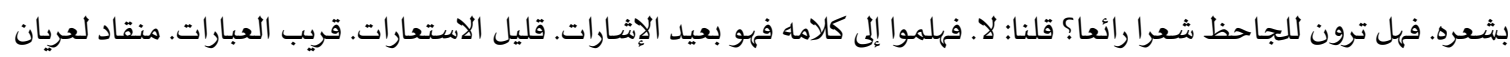

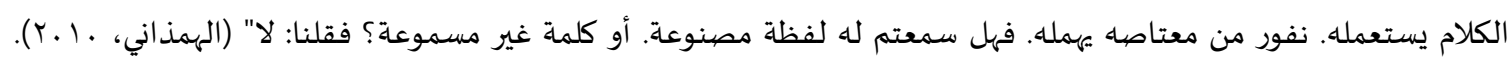

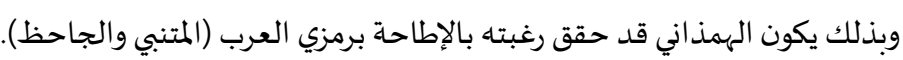

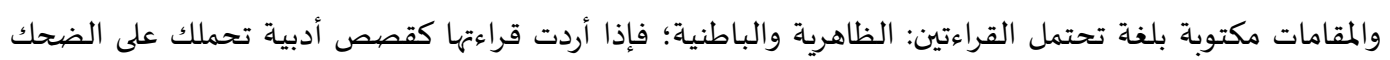

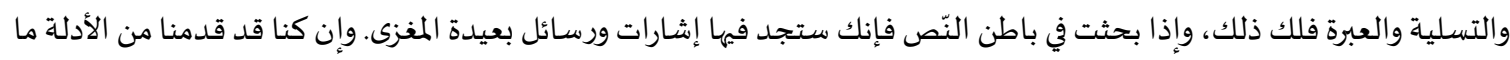

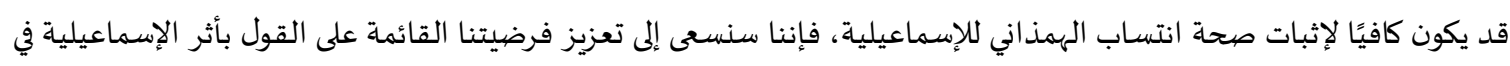

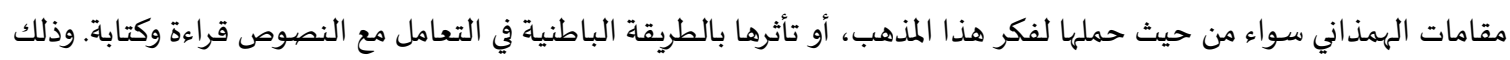

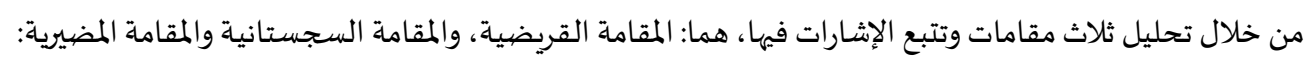

النموذج الأول: المقامة القريضية

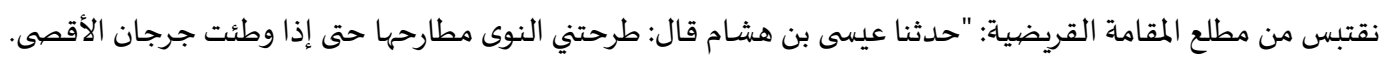

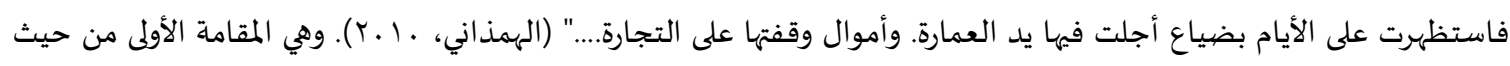

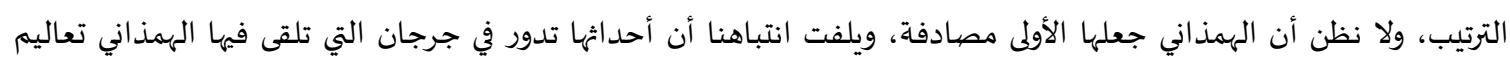

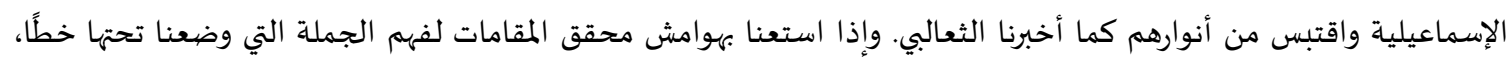

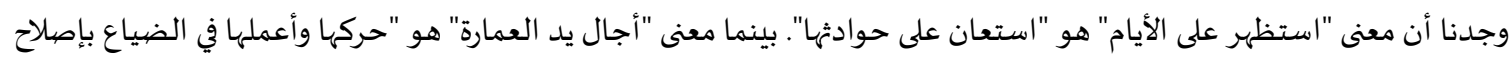

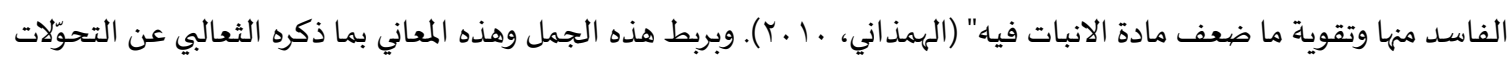

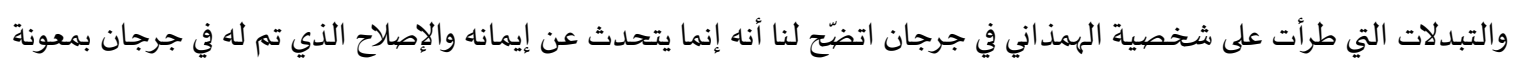

الأنوار الإسماعيلية. 
النموذج الثاني: المقامة السجستانية

تعد هذه المقامة بمثابة وقوف على أطلال الفرس والبكاء عليها؛ فيحدثنا عيسى بن هشام أنها بينما كان في سجستان يبحث

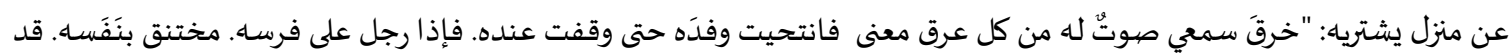

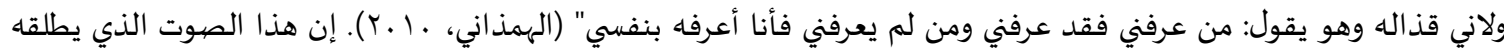

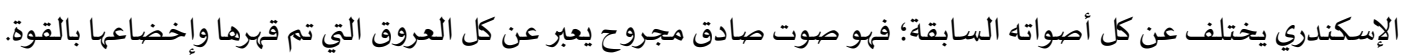

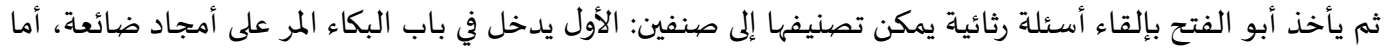

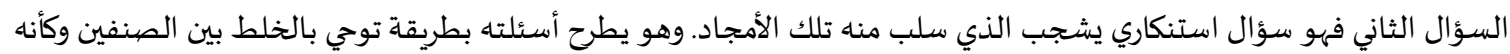
يقصد إلى التمويه والتخفي. يقول في الصنف الأول من الأسئلة: "سلوا عني البلادَ وحصونها. والجبال وحزونها. والأودية وبطونها.

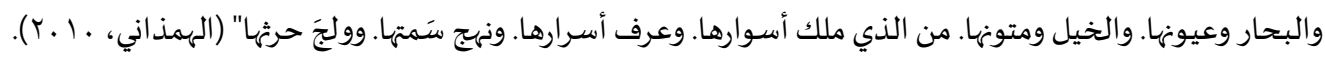

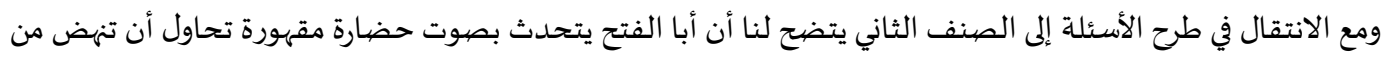

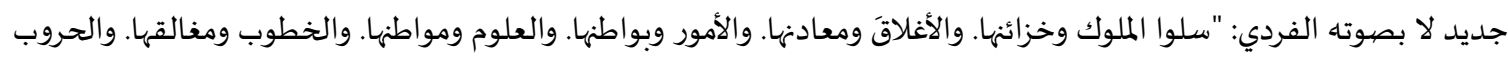

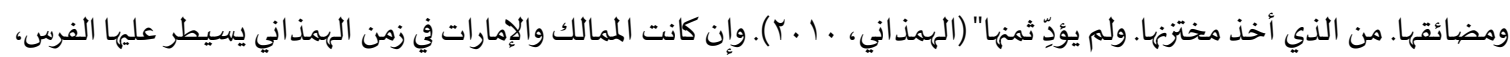

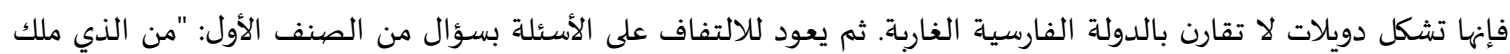

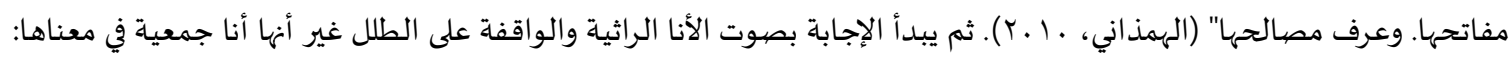

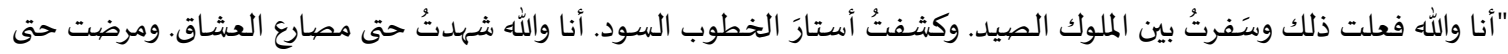

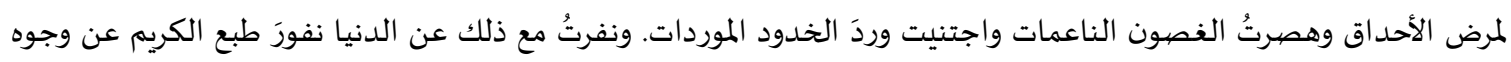

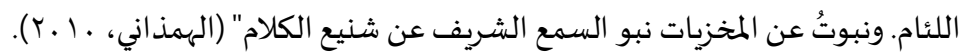

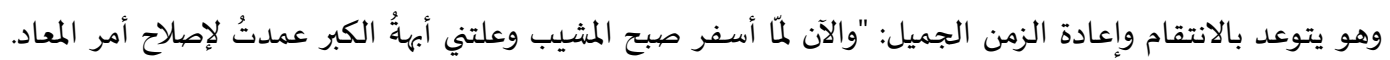

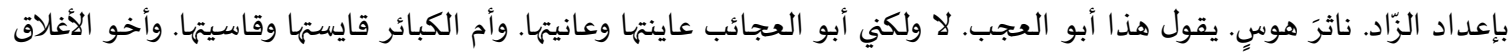

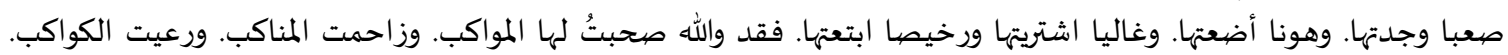

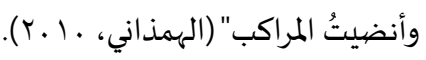
وحينما ينحرف أبو الفتح بالمقامة من مسار الجد إلى مسار الهزل والكدية على عادته، نفاجأ بعيسى بن هشام الذي اعتدنا

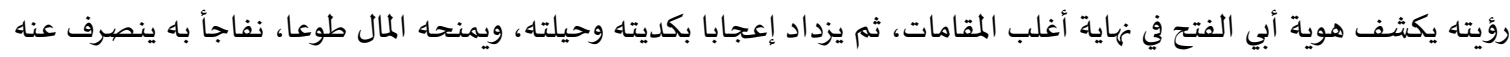

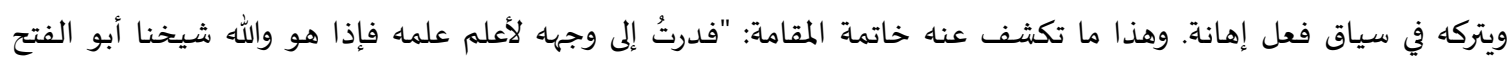

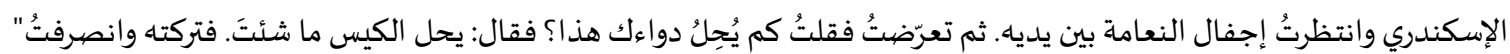

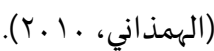

لأن رغبة عيسى بن هشام/ الهمذاني كانت تريد لهذا الصوت أن يواصل خرقه للأسماع، وأن يستمر في المطالبة باستعادة

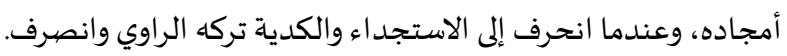

النموذج الثالث: المقامة المضيرية

وفيها يطنى المذهب الشيعي/ الإسماعيلي على النزعة الفارسية. والمقامة سميت المضيرية نسبة إلى المضيرة؛ وهي نوع من

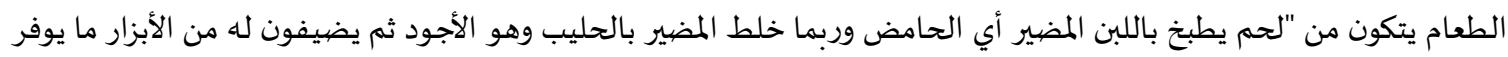

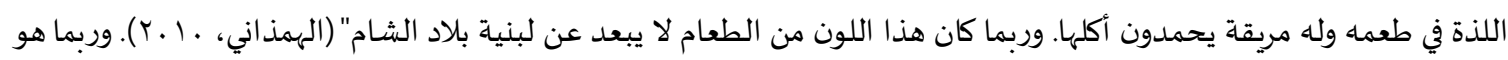

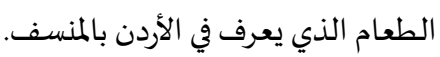

وخلاصية المقامة أن الراوية عيسى بن هشام دُعي مع جماعة من الناس منهم أبو الفتح الإسكندري إلى طعام في البصرة،

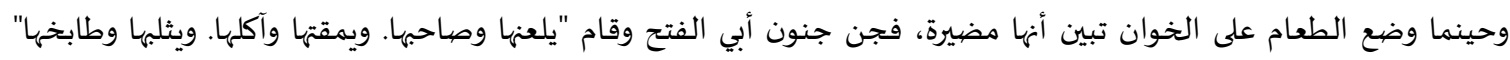

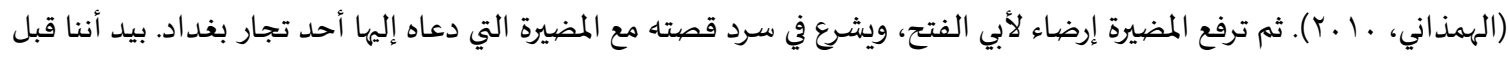

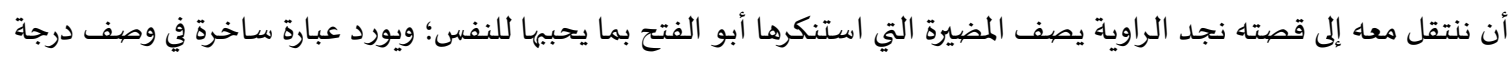

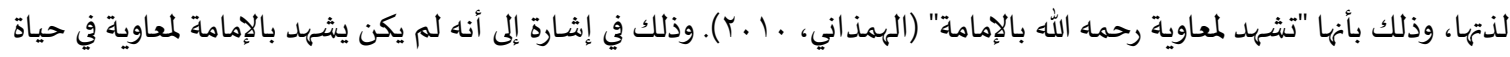

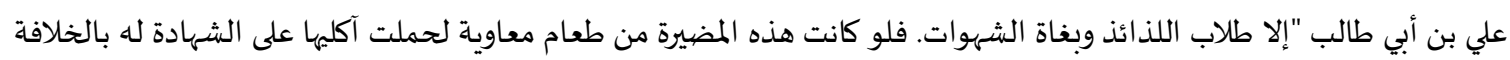

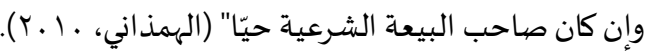


وهذه الإشارة تعبر عن الموقف الشيعي عامة من كل الذين وقفوا إلى صف معاوية بن أبي سفيان؛ بأنهم طلاب شهوات

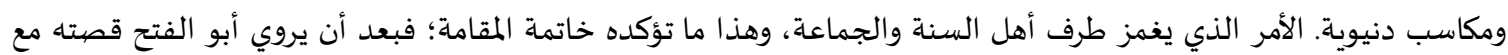

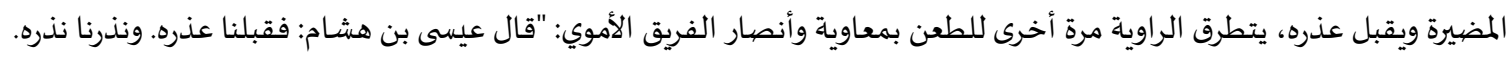

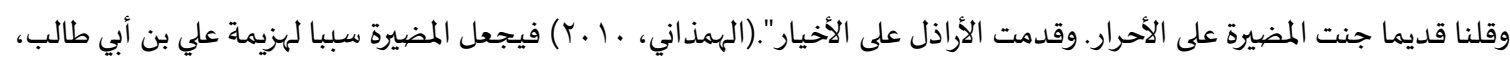
وتقديم أراذل القوم (طلاب اللذائذ والشههوات) على أخيارهم (علي وشيعتهاه).

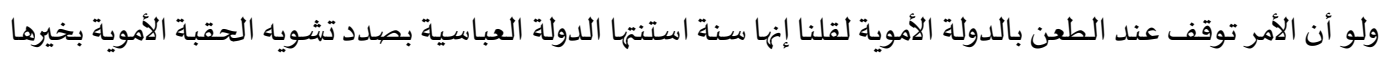

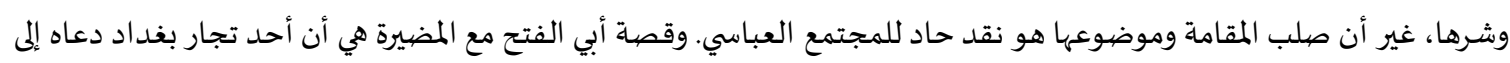

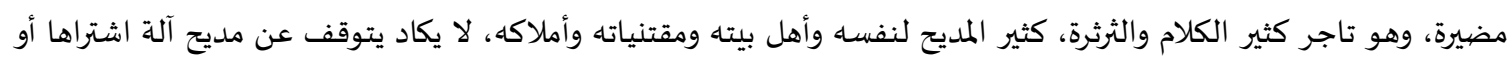

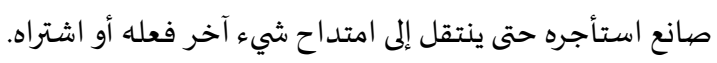

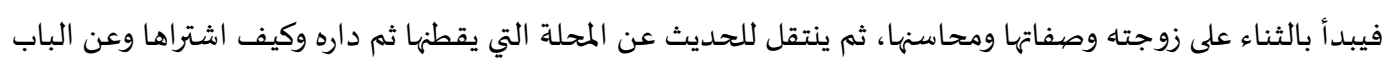

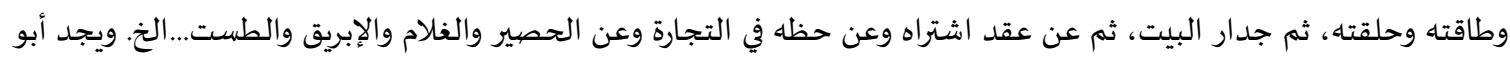

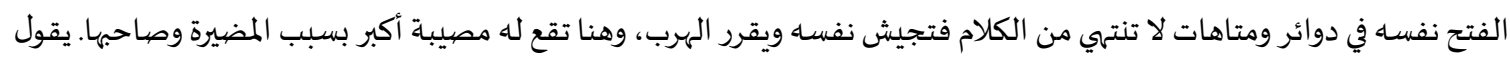

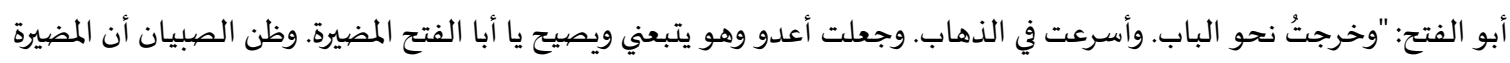

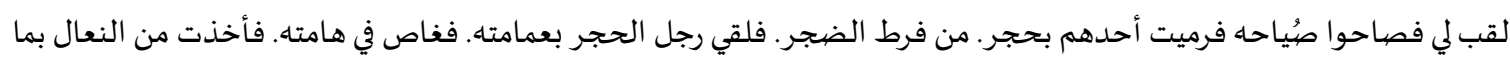

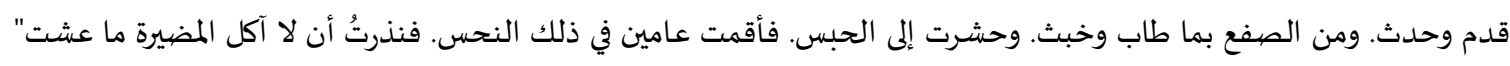

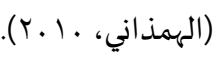

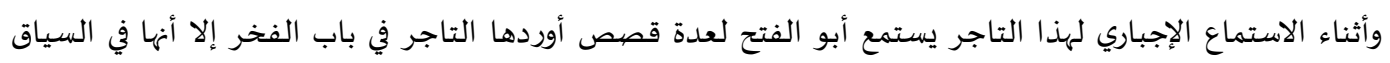

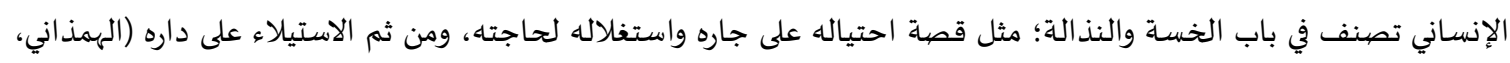

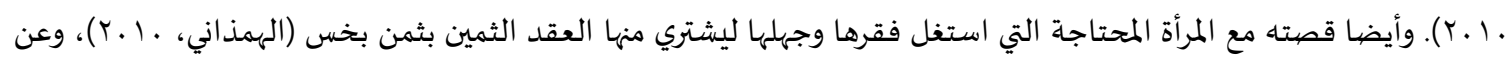

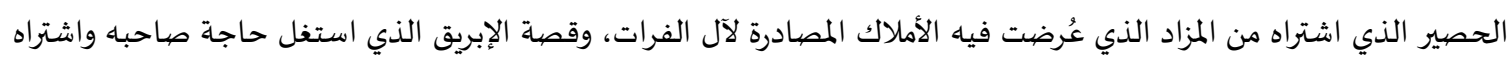

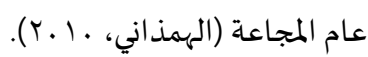

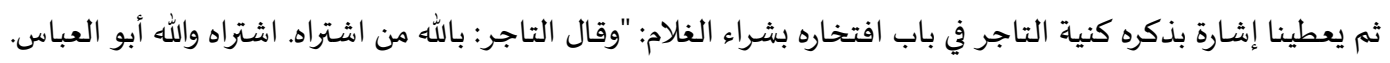

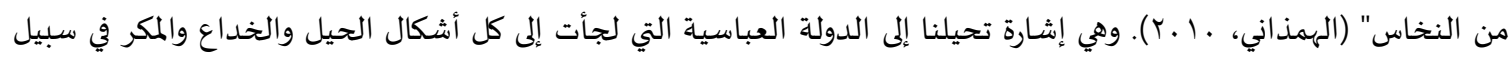

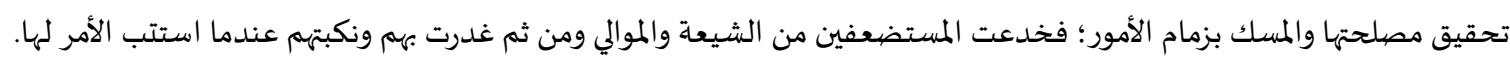

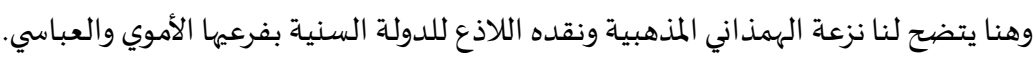

الخاتمة الإشارات والرموز في مقامات بديع الزمان الهمذاني كثيرة وغنية؛ فإذا حاولنا تفكيك المغزي من الأسماء في المقامات (اسم

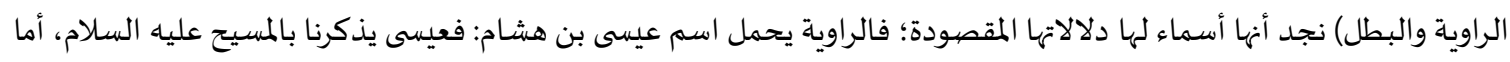

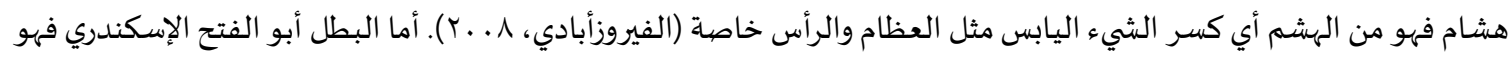

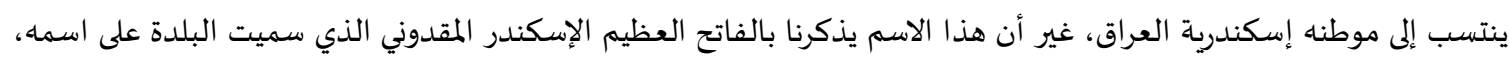

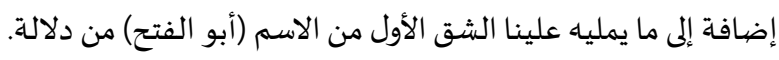

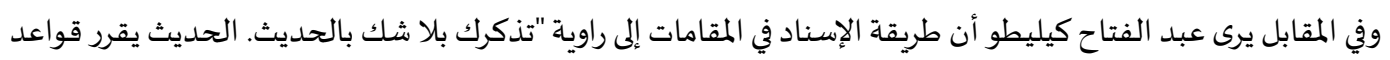

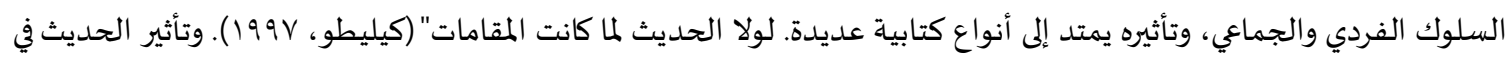

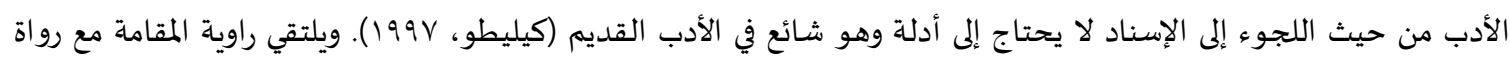

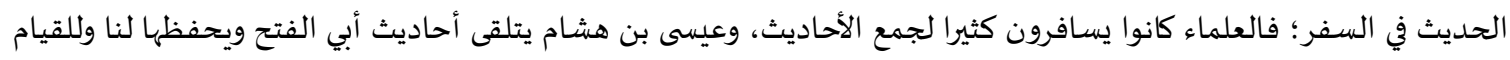

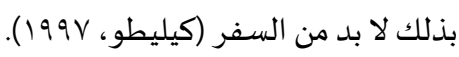

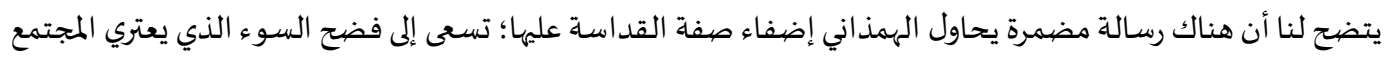

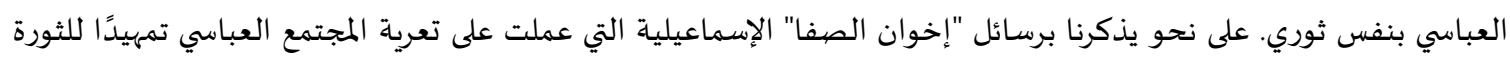

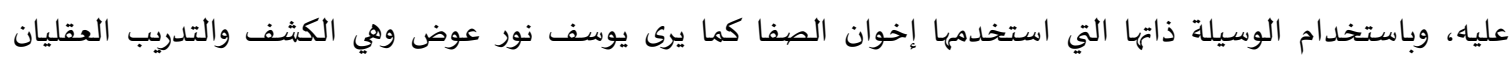

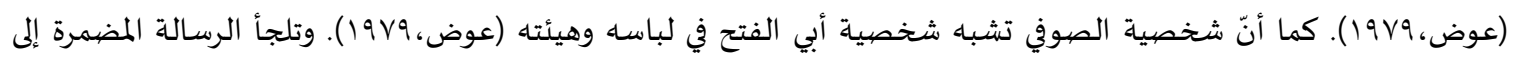


تطعيم المقامات بإشارات ورموز باطنية يرويها شخص يحمل اسم نبي (عيسى) وهو سليل العزة والقوة القادرة على الكسر (الفُرس)،

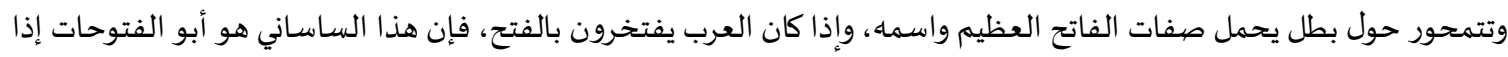

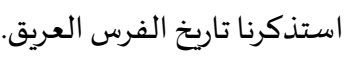

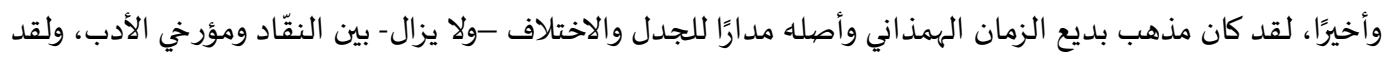

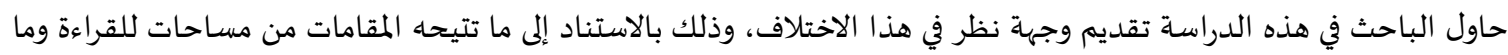

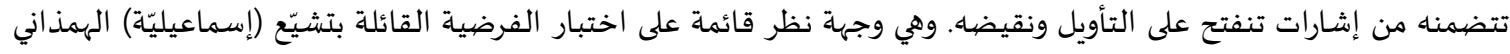

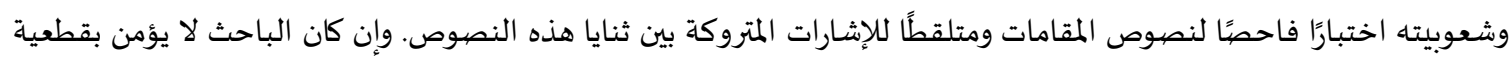

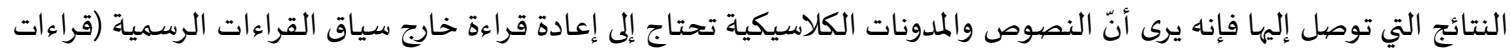

السلطة).

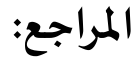

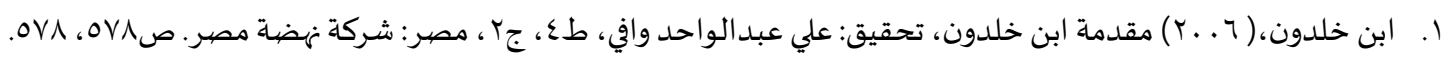

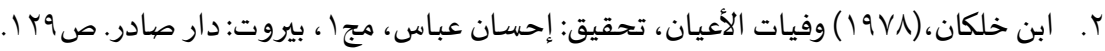

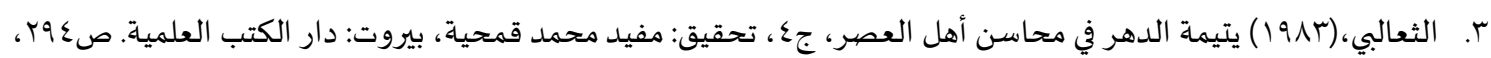

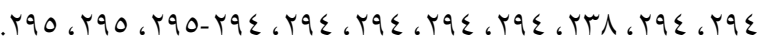

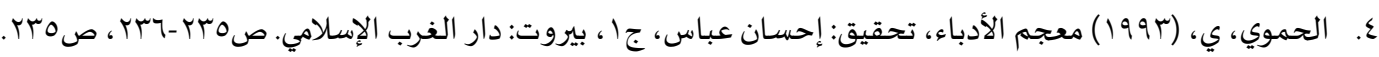

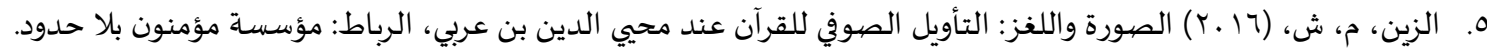

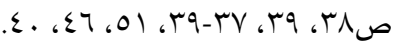

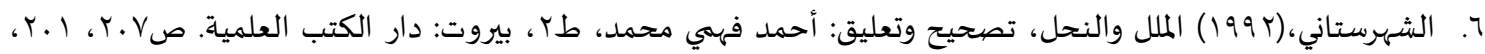

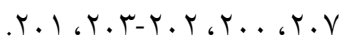

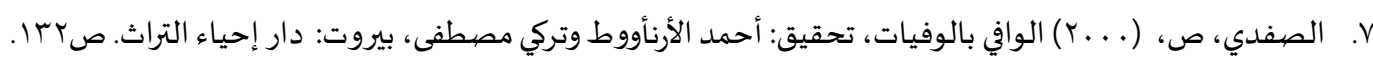

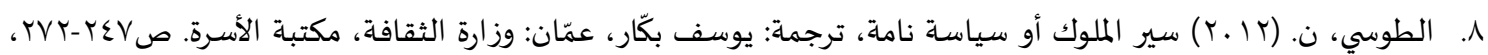

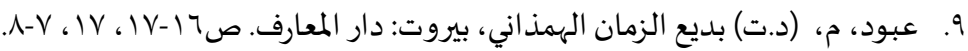

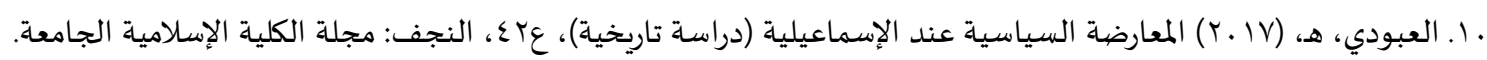

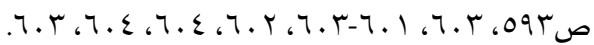

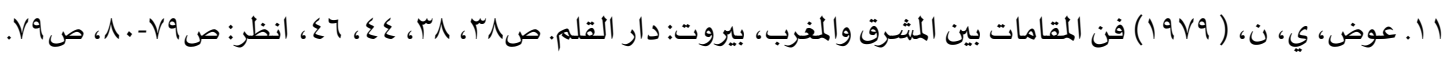

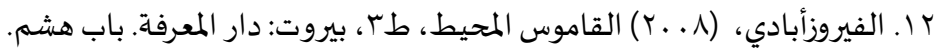

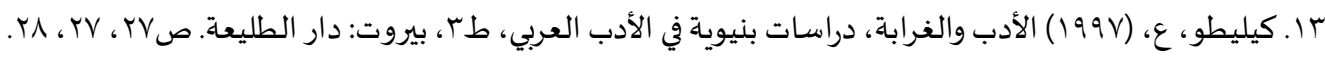

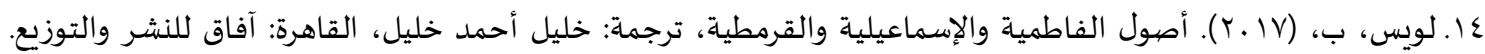

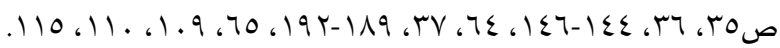

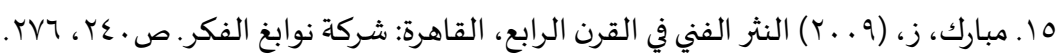

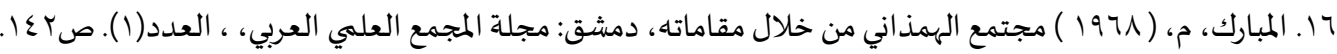

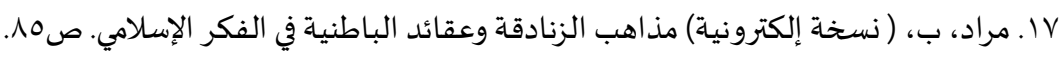

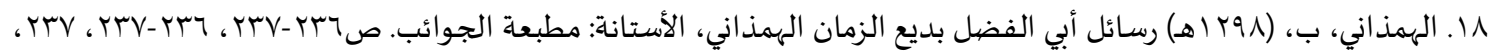

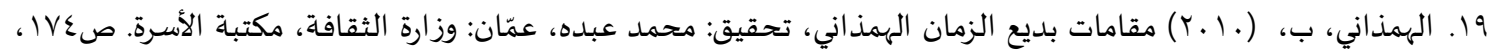

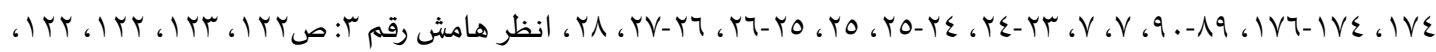

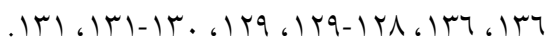


Refaad

رفاد للدراسـات والأبحاث

www.refaad.com
المجلة الدولية للدراسات اللغوية والأدبية العربية

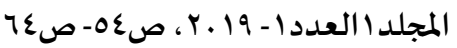

https://doi.org/DOI:10.31559/JALLS2019.1.1.4

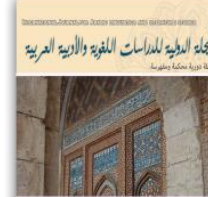

10

\title{
The Anti-Arabism (Shu'ubyya) in the Hamdani Maqamat -An Analytical Study-
}

\section{Rabee' Mahmoud Rabee'}

PhD student- University of Jordan- Jordan rymoon1984@yahoo.com

\begin{abstract}
:
The religious doctrine of Badei-Zaman Al-Hamzani (d. $398 \mathrm{H}$ ) has been controversial, among critics and literature historians. The researcher has attempted to present a point of view on this debate, based on what the Maqamat offers, depending upon the multiplicity of possible readings and textual signs that accept contradictory interpretation. The hypothesis of the research is that Badi'zaman Al-Hamzani was of Ismaili doctrine and Persian origin, that the impact of his doctrine and origin appeared in his Maqamat, and that Hamdani included in the Maqamt gestures that might be interpreted according to the author's the Anti-Arabism tendency. Testing the hypothesis that Alhamdani was Shi'i (Ismaili) and Anti-Arab requires us to read the texts of Maqamat carefully and pick up the implicit gestures and then match and preview them in the light of historical information available about Hamdani in the books of biographies.
\end{abstract}

Keywords: Hamdani, Badeezaman, Anti-Arabism, Maqamat, Ismailia.

\section{References:}

[1] 'bwd. M, Bdy` Ạlzmạn Ạlhmdhạny, Byrwt: Dạr Ạlm'ạrf, pp.16-17, 17, 7-8.

[2] 'wụ. Y, N, Fn Ạlmqạmạt Byn Ạlmsḥrq Wạlmgḥrb, Byrwt: Dạr Ạlqlm, (1979), pp.38, 38, 44, 46, A.nẓr, pp.79-80, Ș79.

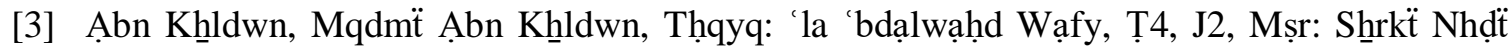
Mṣr, (2006), pp.578, 578.

[4] Ạbn Kḥlkạn, Wfyạt Ạlạ̉ yạn, Tḥqyq: ẠHsạn 'bạs, Mj1, Byrwt: Dạr Ṣạdr, (1978), pp.129.

[5] All bwdy. H, Ạlm'ạrạh Ạlsyạsyh 'nd ẠlạSmạ ylyh (Drạsh Tạrykhyh), '42, Ạlnjf: Mjlï Ạlklyh Ạlạ̣Slạmyh Ạljạm'h, (2017), pp.593, 603, 601-603, 602, 604, 604, 603.

[6] Ạlfyrwzạ̉bạdy, Ạlqạmws Ạlmḥyṭ, Ṭ3, Byrwt: Dạr Ạlm rfft. Bạb Hsḥm, (2008)

[7] Alhmdhany. B, Mqạạat Bdy' Alzmạn Alhmdhany, Thqyq: Mhmd 'bdh, 'mạan: Wzạr Ạlthqậh, Mktbë Ạlạ̉srh, (2010), pp. 174, 174, 174-176, 89-90, 7, 7, 23-24, 24-25, 25, 25-26, 26-27, 28, Ạzrr Hạmsh Rqm 3: pp. 122, 123, 122, 122, 136, 136, 128-129, 129, 130-131, 131.

[8] Ạlhmdhạny. B, Rsạỷl Ạ̉by Ạlfụl Bdy Ạlzmạn Ạlhmdhạny, Ạlạ̉stạnh: Mṭb đ̇ Ạljwậyb, (1298h), pp.236-237, 236-237, 237, 14. 
[9] Ạlḥmwy. Y, M'jm Ạlạ̉dbạ’, Tḥqyq: Ạ̣sạn 'bạs, J1, Byrwt: Dạr Ạlgḥrb Ạlạslạmy, (1993), pp. 235-236, Ș235.

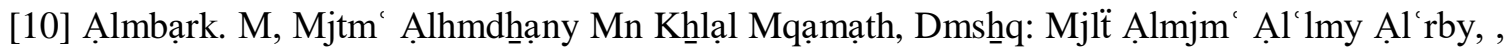
(1)(1968), pp.142.

[11] Ạlșfdy. Ș, Ạlwạfy Bạlwfyạt, Thquyq: Ạ̉ḥmd Ạlạ̉rnạ̉wwț Wtrky Mșṭa, Byrwt: Dạr ẠHyạa' Ạltrạth, (2000), pp.132.

[12] Ạlshhhrstạny, Ạlmll Wạlnḥl, Tṣ̣hỵ Wt'lyq: Ạhmo Fhmy Mḥmd, Ṭ2, Byrwt: Dạr Ạlktb A.l'lmyh, (1992), pp.207, 201, 207, 200, 202-203, 201.

[13] Ạlth́ ạlby, Ytymë Ạldhr Fy Mḥạsn Ạ̉hl Ạl 'ṣr, J4, Tḥqyq: Mfyd Mḥmd Qmḥyh, Byrwt: Dạr Ạlktb Ạl'lmyh, (1983), pp. 294, 294, 294, 238, 294, 294, 294, 294, 294-295, $295,295$.

[14] Ạlțwsy. N, Syr Ạlmlwk Ả̉w Syạsẗ Nạmh, Trjmï: Ywsf Bk̃ạr, 'mạan: Wzạrẗ Ạlthqậfh, Mktbë Ạlạ̉srh, (2012), pp. 247-272, 252.

[15] Ạlzyn. M, Sh̆, Ạlșwrh Wạllghnz: Ạltạ̉wyl Ạlșwfy Llqrận 'nd Mḥyy Ạldyn Bn 'rby, Ạlrbạt: Mw̉ssẗ Mw̉mnwn Blạ Ḥdwd, (2016), pp. 38, 39, 37-39, 51, 46, 40.

[16] Kylyțw. ', Ạlạ̉db Wạlghnrạbh, Drạsạt Bnywyh Fy Ạlạ̉db Ạl'rby, Ṭ3, Byrwt: Dạr Ạlṭly'h, (1997), pp.27, 27, 28.

[17] Lwys. B, Ảṣwl Ạlfạtmyh WạlạSmạ ylyh Wạlqrmțh, Trjmï: Kḥlyl Ảhmmd Kḥlyl, Ạlqạhrh: Ậạq Llnsh̆r Wạltwzy', (2017), pp. 35, 36, 144-146, 64, 37, 189-192, 65, 109, 110, 115.

[18] Mbạrk. Z, Ạlntḥr Ạlfny Fy Ạlqrn Ạlrạb , Ạlqạhrh: Sḥrkẗ Nwạbghh Ạlfkr, (2009), pp. 240, 276.

[19] Mrạd. B, (Nskhh ẠLktrwnyh) Mdhạhb Ạlznạdqh W‘qậd Ạlbạtnyh Fy Ạlfkr ẠlạiSlạmy. pp. 85. 